\title{
Strategic Environmental Assessment and Its Application to Marine Areas beyond National Jurisdiction
}

\author{
Robin Warner
}

\section{Introduction}

Environmental assessment ${ }^{1}$ of human activities with the potential for significant impacts on the marine species, habitats and ecosystems is an essential component of any ocean governance regime. The process of prior environmental impact assessment (EIA) with its recognized stages of screening, scoping and public consultation is critical to minimizing adverse human impacts on these areas and developing suitable mitigation measures for the life of such activities and beyond. It can alert States to the potential for transboundary harm from certain activities in marine areas and in many cases requires States to notify and consult other States where risks to marine areas under their jurisdiction emerge. ${ }^{2}$ EIA is an integral component of a precautionary approach to human activities with the potential for adverse effects on the marine environment. Undertaking prior EIA and ongoing monitoring of activities with the potential for adverse effects on the marine environment is also vital in incorporating environmental concerns into the development process and facilitating sustainable development. ${ }^{3}$ The related but more recently developed process of an overarching strategic environmental assessment (SEA) can be even more beneficial in mitigating the adverse impact of plans, policies and programmes for the development of broader scale marine areas where a range of human activities occur over longer time frames. ${ }^{4}$

1 The term 'environmental assessment' in this essay includes the related processes of prior environmental impact assessment (EIA), transboundary environmental impact assessment (TEIA) and strategic environmental assessment (SEA).

2 N Craik, The International Law of Environmental Impact Assessment (Cambridge University Press, 2008) 71; P Birnie, A Boyle and C Redgwell, International Law and the Environment (3rd ed, Oxford University Press, 2009) 165.

3 Birnie et al., above (n 2), 165 .

4 Craik, above (n 2), 78. 
Taking this into account, the implementation of SEA is even more critical in the vast ocean areas beyond national jurisdiction in which some of the world's most rare and fragile ecosystems and key migratory species are found in both the water column and deep seabed and where scientific knowledge is still at an early stage of development. SEA, as a process which seeks to put in place longer term environmental objectives for different regions and sectoral activities, is uniquely suited to the challenges arising from conservation and sustainable use of marine biodiversity in areas beyond national jurisdiction (ABNJ).

The process initiated by the UN General Assembly (UNGA) in UNGA Resolution $69 / 292^{5}$ to develop the elements of an international legally binding instrument (ILBI) for conservation and sustainable use of marine biodiversity in ABNJ has mandated that negotiations to develop the new ILBI should address the four elements of a package deal agreed by States in 2011. These elements comprise 'marine genetic resources including questions on the sharing of benefits, measures such as area based management tools, including marine protected areas, environmental impact assessments and capacity building and the transfer of marine technology'.6 UNGA Resolution 69/292 also stipulates that the process to develop the ILBI should not undermine existing relevant legal instruments and frameworks and relevant global sectoral and regional bodies. ${ }^{7}$ The Preparatory Committee for the ILBI which met four times in 2016 and 2017, established a working Group on the EIA element of the package which also addressed the inclusion of SEA provisions in a future ILBI. ${ }^{8}$ Although the participants in all four Preparatory Committee meetings discussed the concept of SEA and how it might be implemented in ABNJ, no

5 United Nations General Assembly (UNGA), Resolution 69/292: Development of an International Legally Binding Instrument under the United Nations Convention on the Law of the Sea on the Conservation and Sustainable Use of Marine biological Diversity of Areas beyond National Jurisdiction, resolution adopted by the General Assembly, adopted 19 June 2015 .

6 Ibid para 2.

7 Ibid para 3 .

8 United Nations Division for Ocean Affairs and the Law of the Sea (UndoAlos), 'Preparatory Committee established by General Assembly resolution 69/292: Development of an international legally binding instrument under the United Nations Convention on the Law of the Sea on the conservation and sustainable use of marine biological diversity of areas beyond national jurisdiction', http://www.un.org/Depts/los/biodiversity/prepcom.htm (all websites accessed 12 October 2020 unless otherwise noted). 
consensus was reached on whether SEA would be included in the ILBI and likely sEA elements. ${ }^{9}$

This chapter will discuss the concept of SEA and potential elements in an SEA process. It will examine the relationship between EIA and SEA and the relevance of SEA to marine spatial planning. Some concrete examples of SEA in a marine context will also be considered. Finally, it will envision how SEA might be implemented in ABNJ and highlight key points on SEA which have emerged from the Preparatory Committee meetings for the ILBI. The ILBI negotiations represent a historic opportunity to lay the foundations for a more scientifically informed, integrated and cross sectoral framework to conserve and sustainably use marine biodiversity in ABNJ. An effective SEA process can play a vital role in informing States and the multiple stakeholders involved in conserving and sustainably using marine biodiversity in $\mathrm{ABNJ}$ of the environmental implications of particular plans, policies and programmes.

\section{The Concept of Strategic Environmental Assessment}

SEA is a proactive process usually carried out by a public or governmental authority, which identifies and evaluates the significant environmental and sustainability implications of particular plans, programmes and policies to ensure that they are fully considered and addressed at the earliest stages of decision making. ${ }^{10}$ It typically involves the setting of an overarching environmental vision and objectives for a particular geographic region and activities within that region. ${ }^{11}$ A broad range of alternative courses of action to achieve the specified objectives are then developed and each alternative is assessed against specific criteria within the context of the broader environmental vision and objectives. Alternative courses of action are then assessed against criteria such as sustainability measures and acceptable levels of environmental change for particular species, habitats and ecosystems. On the basis of this assessment, the most desirable courses of action are selected and implemented in

9 IISD, 'Summary of the Fourth Session of the Preparatory Committee on Marine Biodiversity beyond Areas of National Jurisdiction' (2017) 25(141) Earth Negotiations Bulletin, http://enb.iisd.org/vol25/enb25141e.html.

10 BF Noble, 'Strategic Environmental Assessment: What Is It? \& What Makes It Strategic?' (2000) 2(2) Journal of Environmental Assessment Policy and Management 203-224, 205; RAA Verheem and JAMN Tonk, 'Strategic Environmental Assessment: One Concept, Multiple Forms' (2000) 18(3) Impact Assessment and Project Appraisal (2000) 177-182, 177. Noble, ibid 206. 
policies, plans and programmes for that area. One of the main benefits of SEA is that it provides a means of anticipating and avoiding cumulative adverse impacts on the environment. ${ }^{12}$ SEA is still at an early stage of implementation, with the 2003 Protocol on Strategic Environmental Assessment in a Transboundary Context (Kiev Protocol) ${ }^{13}$ being the principal international instrument on this process and the European Union (EU) Directive on $\mathrm{SEA}^{14}$ as a key regional example of its implementation in policy. There is currently no customary or conventional international law obligation to carry out SEA for plans, programmes and policies intended to be implemented in ABNJ. The objective of the EU Directive on SEA is stated as being 'to provide for a high level of protection of the environment and to contribute to the integration of environmental considerations into the preparation and adoption of plans and programmes with a view to promoting sustainable development, by ensuring that ... an environmental assessment is carried out of certain plans and programmes which are likely to have significant effects on the environment.'.15

\section{Elements of Strategic Environmental Assessments}

SEA instruments and policy directives such as the Kiev Protocol and the EU Directive on SEA contain provisions prescribing policies, plans and programmes which are subject to SEA processes. These are known as screening provisions and refer to those policies, plans and programmes likely to have significant effects on the environment. In some cases they provide a more specific listing of those plans and programmes for which an SEA process is mandatory. The Kiev Protocol describes some of the key elements in an SEA process in its definition of SEA. These include the evaluation of the likely environmental and health effects of a policy, plan or programme through the determination of the scope of an environmental report and its preparation, the carrying out of public participation and consultations, and the taking into account of the environmental report and the results of the public participation

\footnotetext{
12 M Elliott, Environmental Impact Assessment in Australia. Theory and Practice (6th ed, Federation Press, 2014) 69.

13 Protocol on Strategic Environmental Assessment to the Convention on Environmental Impact Assessment in a Transboundary Context, 21 May 2003, entered into force 11 July 2010, (2685 UNTS 140).

14 Directive 2001/42/EC of the European Parliament and of the Council of 27 June 2001 on the assessment of the effects of certain plans and programmes on the environment (SEA Directive), OJ L 197 (21 July 2001).

Ibid Art 1.
} 
and consultations in the policy plan or programme. ${ }^{16}$ The ILBI could prescribe that States Parties or groups of States Parties intending to implement plans, policies and programmes in ABNJ should undertake an SEA. The scientific advisory body or technical committee of the ILBI could develop voluntary or mandatory guidelines specifying the key elements in an SEA process. In some cases, States Parties could work in conjunction with international organizations such as the International Seabed Authority (ISA), International Maritime Organization, Intergovernmental Oceanographic Commission and regional fisheries management organizations (RFMOS) on SEAs relating to particular sectors or regions in $\mathrm{ABNJ}$.

In practice, SEA is generally understood as comprising a flexible framework of key elements which support decisions on development by integrating environmental considerations into the decision-making process. ${ }^{17}$ The elements in an SEA process tend to be less prescribed and more iterative than in EIA processes. Elements in an SEA process include an array of 'analytical and participatory approaches' designed to 'integrate environmental considerations into policies, plans and programmes and evaluate the interlinkages with economic and social considerations. ${ }^{18}$ Different tools can be employed at different stages as part of an SEA according to the context of the policy, plan or programme being assessed. These include tools to predict environmental and socio-economic effects, tools to ensure full participation of stakeholders and tools for analysing and comparing options. The OECD Guide to Understanding SEA in the development context provides some useful examples of the different types of tools that can be employed.

First, there are tools for predicting environmental and socio-economic effects. These include: modelling or forecasting of direct environmental effects; matrices and network analysis; participatory or consultative techniques; and geographical information systems (GIS), as a tool to analyse, organise and present information. In the ABNJ context, developing these predictive tools particularly for environmental effects and GIS systems could well involve the international scientific community and technical experts from bodies such as the IOc. Bodies such as the Deep Ocean Stewardship Initiative (DOSI) and the

16 Ibid Arts 6-12.

17 M do Rosario Partidario, Strategic Environmental Assessment Better Practice Guide: Methodological Guidance for Strategic Thinking in SEA (Portuguese Environment Agency and Redes Energeticas Nacionais, 2012) 11.

18 Organisation for Economic Co-operation and Development (OECD), Applying Strategic Environmental Assessment. Good Practice Guidance for Development Co-operation (OECD, 2006) 32 . 
Global Ocean Biodiversity Initiative (GOBI) are already engaged in supporting the ILBI negotiations and are likely to continue that support in the post intergovernmental conference phase through any scientific advisory body established under the ILBI.

Second, there are tools for ensuring full stakeholder engagement. These include: stakeholder analysis to identify those affected and involved in the policy, plan or programme decision; consultation surveys; and consensus building processes. An important task for the Conference of Parties (COP) of the ILBI and its supporting committees will be to establish a register of relevant stakeholders for processes such as SEA. This is likely to include States Parties, relevant global and regional intergovernmental and non-governmental organizations, representative industry bodies and in some cases, coastal communities with relevant interests in high seas areas such as the Pacific island communities surrounding the high seas enclaves in the Pacific. Stakeholder engagement tools designed to engage all these actors could also be developed by the COP of the ILBI and its supporting committees.

Finally, there are tools for analysing and comparing options: Scenario analysis and multi-criteria analysis; risk analysis or assessment; cost benefit analysis; and opinion surveys to identify priorities. ${ }^{19}$ Likewise this third tranche of tools could be developed by the scientific and technical committees supporting the COP of the ILBI. A selection of these tools could be used according to the context of the SEA with each of the broad general categories being represented in the mix.

A further element in any SEA process is ongoing monitoring of the implementation of particular policies, plans and programmes to determine any adverse unforeseen environmental or health effects so as to undertake remediation. ${ }^{20}$ This again raises questions as to who would bear responsibility for ongoing monitoring of the environmental objectives articulated in an SEA process relating to policies, plans and programmes in $\mathrm{ABNJ}$. This may entail including a requirement in the ILBI for State Party proponents of particular plans, policies and programmes in ABNJ to make periodic reports to the ILBI scientific and technical committee and ultimately the COP of the ILBI on how the SEA objectives are being met.

$19 \quad$ Ibid 33.
$20 \quad$ Elliott, above (n 12), 70-71. 
SEA proactively examines a wide range of alternatives for policies, plans and programmes and selects the preferred course of action with a broader environmental and planning vision in mind. In contrast, EIA is more confined and concrete in focus determining the likely environmental impacts of a particular project or development. EIA will typically propose alternatives and specify mitigation measures to avoid the most negative environmental impacts of a project or development. SEA is a more overarching and flexible concept than EIA allowing for a more comprehensive and forward looking assessment of environmental considerations at the policy, planning and programme level. ${ }^{21}$ While EIA is often location specific and limited in time, SEA processes broaden the spatial and temporal range of environmental assessment often being applied to whole sectors of activity or geographic areas as an institutionalized part of decision-making on a long-term basis. This does present considerable resource and logistic challenges in the context of ABNJ in view of the vast areas and distances from land involved. States Parties will need to work creatively with relevant international organizations and industry actors to undertake SEA processes. Ideally, SEA and EIA should be vertically integrated or tiered with environmental considerations being taken into account at the policy, plan and programme level and then flowing down to the project level. ${ }^{22}$ In descriptions of the relationship between SEA and EIA, EIAS are often described as being nested within a particular SEA. In practice and in the past, this has not always happened, with EIAs for specific projects often occurring in the absence of a broader environmental vision for the particular marine region and associated activities and industries. For ABNJ, EIAs that have already been undertaken in sectors such as deep seabed mining may well inform subsequent sEAs for broader regions and for the sector more generally.

21 Noble, above (n 10), 204-205; Partidario, above (n 17), 23-24; T Greiber and M Knodel (with comments from Robin Warner), 'An International Instrument on Conservation and Sustainable Use of Marine Biodiversity in Areas beyond National Jurisdiction. Exploring Different Elements to Consider. Paper viI-Relation between Environmental Impact Assessments, Strategic Environmental Assessments and Marine Spatial Planning' (IUCN, Commissioned by the German Federal Agency for Nature Conservation, 2015).

22 Craik, above (n 2), 156; S Marsden, 'Coordinating Strategic Environmental Assessments of Marine and Terrestrial Plans: Australian Experience in the Sub-Antarctic' in R Warner and S Marsden (eds), Transboundary Environmental Governance: Inland Coastal and Marine Perspectives (Ashgate Publishing, 2012) 208. 
Marine spatial planning (MSP) has been defined by UNESCO as 'a public process of analyzing and allocating the spatial and temporal distribution of human activities in marine areas to achieve ecological, economic, and social objectives that usually have been specified through a political process. ${ }^{23}$ It is emerging as a tool for accommodating competing uses of the marine areas while maintaining the environmental integrity of these areas. ${ }^{24}$ Ideally, an SEA process would precede MSP for a particular coastal or marine region. The SEA vision and objectives for a particular region would provide some overarching parameters for MSP in the same region. For instance, an ecosystem based approach endorsed in the SEA vision and objectives for a particular coastal or marine region could be one of the guiding principles for MSP in that region. MSP can also be a more fine-grained process and in some cases a more localized process than SEA. It will frequently take into account the detailed spatial and temporal factors affecting the diverse human activities in particular marine areas and the positive and negative implications of allowing or restricting certain uses over time. In most regions of ABNJ, MSP is either non-existent or at a very nascent stage of development. While regions such as the Antarctic and North East Atlantic have established some marine protected areas which are binding on States Parties to the 198 o Convention on the Conservation of Antarctic Marine Living Resources ${ }^{25}$ and the 1992 Convention for the Protection of the Marine Environment of the North-East Atlantic (OSPAR Convention), ${ }^{26}$ the more detailed MSP processes characteristic of some coastal and marine regions under national jurisdiction are not present as yet.

\section{Examples of SEA in a Marine Context}

This section will consider some examples of SEA s conducted in coastal and marine regions under national jurisdiction as points of comparison for future practice in $\mathrm{ABNJ}$ as there are few, if any, examples of SEAs in ABNJ. The conduct of an SEA for a particular coastal or marine region prior to resource exploitation

23 United Nations Educational and Scientific Organization (unesco), Marine Spatial Planning Programme', http://msp.ioc-unesco.org/.

24 F Douvere, 'The Importance of Marine Spatial Planning in Advancing Ecosystem-based Sea Use Management' (2008) 32(5) Marine Policy 762-771, 762.

25 Adopted 20 May 1980, in force 7 April 1981, 1329 UNTS 47.

26 Adopted 22 September 1992, in force 25 March 1998, 2354 UNTs 67. 
can establish a sustainable policy context for future development. An SEA provides for the proper consideration of alternatives and cumulative impacts as well as engaging those affected by proposed developments in a shared environmental, economic and social vision for the region at an early stage in decisionmaking. As discussed above, SEAs in ABNJ would need to engage multiple stakeholders depending on the region and context including relevant intergovernmental and non-governmental organizations such as ISA, IMO, IOC, IUCN, WWF and RFMOs, proximate coastal communities with interests such as fisheries in the relevant $\mathrm{ABNJ}$ and relevant industry actors and their representative bodies. SEAs in marine areas can provide important background information for project based EIAs such as the existence of ecologically or biologically sensitive marine areas (EBSAs) ${ }^{27}$ and vulnerable marine ecosystems (VMEs) ${ }^{28}$ and patterns of multi-sectoral use in the region. Examples of SEAs applied to resource development in waters under national jurisdiction are increasing internationally. Many jurisdictions conduct SEAs before opening up offshore areas to oil and gas development including the United States, Canada, Norway and Denmark. ${ }^{29}$ Member States of the European Union are also required to conduct SEAs for new offshore energy development plans, such as for wind and wave energy, which are likely to have significant environmental effects and which meet certain thresholds. The requirement also extends to fisheries, energy, industry, transport, waste management and telecommunications plans and programmes. ${ }^{30}$ In Australia, the 1999 Environment Protection and Biodiversity Conservation Act (E PBC) (Cth) requires that all Commonwealth managed fisheries undergo SEA before new management arrangements are brought into effect, and that all fisheries with an export component undergo assessment to determine the extent to which management arrangements will ensure that the fishery is managed in an ecologically sustainable way. ${ }^{31} \mathrm{~A}$ study of the role of SEA in the tidal energy industry in the Bay of Fundy, Nova Scotia, Canada by Meinhard Doelle makes a number of recommendations on the characteristics of an effective SEA:

27 Convention on Biological Diversity (CBD), 'Ecologically or Biologically Significant Areas (EBSAs)', https://www.cbd.int/ebsa/.

28 Food and Agricultural Organization of the United Nations (FAO), 'Vulnerable Marine Ecosystems', http://www.fao.org/in-action/vulnerable-marine-ecosystems/en/.

29 M Doelle, N Bankes and L Porta, 'Using Strategic Environmental Assessments to Guide Oil and Gas Exploration Decisions: Applying Lessons Learned from Atlantic Canada to the Beaufort Sea' (2013) 22(1) Review of European Community and International Environmental Law 103-116, 103 .

30 SEA Directive, above (n 14), Art 3.

31 Marsden, above (n 22), 211. 
- The SEA should be applied early and proactively;

- The SEA should integrate environmental, social and economic aspects and be integrated within larger planning and decision making processes;

- The SEA should take into account its place within the other tiers or levels of assessment. For instance SEA should inform future EIA processes at the project level;

- The SEA should be guided by regulatory, policy and other forms of guidance rather than being ad hoc;

- The SEA process should be flexible and adaptable;

- The SEA process should be transparent and include opportunities for public involvement throughout;

- The most effective incentives must be in place to ensure that the SEA is adhered to;

- The SEA must be followed up in terms of performance, as well as effects, compared with predictions and in terms of improving future policies, plans and programmes as well as improving the assessment process itself; and

- The political will necessary for putting in place and implementing an SEA must exist. Decision makers must be participants in the design establishment and implementation of the SEA. ${ }^{32}$

While these conditions may be valid for a coastal area under national jurisdiction with established governmental authorities and identifiable stakeholders, they would present considerable challenges in an $\mathrm{ABNJ}$ context. The initial implementation of SEA processes in ABNJ is likely to be largely experimental and there will be multiple gaps in the governance framework for particular regions of ABNJ in terms of broader planning processes and regulatory guidance. Nevertheless, the above list of conditions does provide some starting points for developing guidelines on SEA in ABNJ.

\section{$7 \quad$ Envisioning SEA in ABNJ}

An SEA process may be most appropriately employed where a trigger arises as a result of proposed sectoral developments or plans for a particular region of $A B N J$ with the potential for significant impacts on the marine environment. For ABNJ there is currently no institution with overarching responsibility for

32 M Doelle, 'Role of Strategic Environmental Assessments in Energy Governance: A Case Study of Tidal Energy in Nova Scotia's Bay of Fundy' (2009) 27(2) Journal of Energy and Natural Resources Law 112-144, 139-142. 
the protection of the marine environment of $\mathrm{ABNJ}$ and the conservation and sustainable use of its biodiversity. SEAs can therefore only be triggered by the few sectoral or regional authorities with areas of ABNJ under their jurisdiction such as the ISA or bodies within the Antarctic Treaty system such as the Committee on Environmental Protection of the Antarctic Treaty with all the attendant political difficulties that entails. ${ }^{33}$ When the ILBI enters into force, States Parties to the ILBI either individually or as groups that are proponents of a particular plan, programme or policy for a region or sector of ABNJ could be required to undertake an SEA for such plans, policies and programmes. The commercial exploitation of deep seabed minerals in different regions of the Area such as the Clarion-Clipperton Zone, the Mid Atlantic Ridge or the Indian Ocean provides a potential scenario for the triggering of an SEA by the ISA. The objective of an SEA in this instance might be to analyse the key environmental, economic and sustainability issues and problems involved in the commercial exploitation of deep seabed minerals in these regions with a view to minimizing the environmental harm to marine biodiversity caused by such developments. A number of analytical methods could be employed for the SEA taking into account that no specific sequence or method has been specifically mandated in State practice to date. Initially an SEA might involve the development of a problem framework which maps the key environmental, economic and sustainability issues and problems associated with the development of deep seabed minerals in a particular region of ABNJ ${ }^{34}$ This might include in broad terms the marine biodiversity and natural resources of the region, ecologically and biologically sensitive areas within the region, the medium and long-term economic potential of deep sea mining in the region, the economic potential of other industries within the same region such as deep sea fisheries and bioprospecting and the cumulative environmental impacts associated with deep seabed mining in the region.

A governance framework could be developed by the body triggering the SEA to identify institutional responsibilities for policy, plan or programme implementation, governance instruments, mechanisms for institutional cooperation and the stakeholders that need to be engaged in any participative or collaborative process. ${ }^{35}$ In the deep seabed mining example this is likely to include

33 RM Roura and AD Hemmings, 'Realising Strategic Environmental Assessment in Antarctica' (2011) 13(3) Journal of Environmental Assessment and Policy and Management 483-513, explores the political tensions and different national perspectives on strategic objectives for the Antarctic which stand in the way of realizing SEA in the Antarctic.

35 Ibid 46. 
but not be limited to the ISA itself, exploitation contractors, RFMOs, regional seas organizations with ABNJ responsibilities, related international organizations such as the Food and Agriculture Organization of the United Nations, Convention on Biological Diversity (CBD $)^{36}$ and Convention on Migratory Species, ${ }^{37}$ relevant intergovernmental organizations (IGO s) such as IUCN and environmental non-governmental organizations (NGOS). The ISA already has MOU s with bodies such as the IMO and OSPAR and is developing and updating regional environmental plans in conjunction with relevant international and regional organizations for areas of the deep seabed under its jurisdiction including the Mid-Atlantic Ridge and the Clarion-Clipperton Zone. ${ }^{38}$ A strategic reference framework could also be prepared to map the overarching law and policy documents which set the context for the SEA. ${ }^{39}$ This could include globally endorsed policies such as the UN Sustainable Development Oceans Goal $14,{ }^{40}$ the RIO +20 commitments on ocean sustainability, ${ }^{41}$ relevant articles of the UN Convention on the Law of the Sea, ${ }^{42}$ the potential new internationally legally binding instrument for conservation and sustainable use of marine biodiversity in ABNJ and the СвD. The problem, governance and strategic reference frameworks together could provide the necessary context for developing critical decision factors ( $\mathrm{CDF}$ ) or key integrative themes upon which the SEA is based. These documents could all be prepared in conjunction with the relevant stakeholders identified above and particularly those most closely involved in developing policy, plans and programmes for the $\mathrm{ABNJ}$ regions in question. ${ }^{43}$

36 Adopted 5 June 1992, in force 29 December 1993, 176o UnTS 79.

37 Convention on the Conservation of Migratory Species of Wild Animals, adopted 23 June 1979, in force 1 November 1983, 1651 UNTS 333 .

38 The International Seabed Authority held a workshop on Development of a Framework for Regional Environmental Management Plans (REMPs) for Polymetallic Sulphide Deposits between 27 to 29 June 2018 which will issue a Technical Study, https://www.isa.org.jm/ workshop/workshop-developing-framework-regional-environmental-managementplans-remps-polymetallic.

39 Partidario, above (n 17), 46.

40 United Nations, Department of Economic and Social Affairs, Sustainable Development Knowledge Platform, 'Sustainable Development Goal 14 (Life below Water)—Conserve and sustainably use the oceans, seas and marine resources for sustainable development', https://sdgs.un.org/goals/goali4.

41 United Nations, Department of Economic and Social Affairs, Sustainable Development Knowledge Platform, 'United Nations Conference on Sustainable Development, Rio+2o', https://sustainabledevelopment.un.org/riozo.html.

42 Adopted 10 December 1982, in force 16 November 1994, 1833 UNTS 3.

43 Partidario, above (n 17), 48. 
In the deep seabed mining example, the CDF s could include conservation of ecological systems, development of deep seabed minerals in new areas of ABNJ and transparent governance. These key integrated themes upon which the SEA is based would then be assessed against relevant criteria and indicators. ${ }^{44}$ For instance, in the case of ecological systems, what approaches would be necessary to minimise biodiversity loss in a particular region? In the case of governance, what models of institutional cooperation and stakeholder engagement would be optimal for achieving transparent governance in the ABNJ deep seabed mining sector? Strategic pathways or options are then identified including the assessment of opportunities and risks involved in adopting different options. ${ }^{45}$ Different environmental, sustainability, fiscal and governance implications will follow from particular pathways. A number of recommendations for strategic pathways to achieve the strategic objectives of the SEA could then be made in a report to the key planning authority, in this case the ISA, and to other stakeholders. A follow up programme and monitoring and evaluation guidelines are critical components of SEA. ${ }^{46}$ This could involve mechanisms such as monitoring the state of the environment in the relevant region of ABNJ on a regular basis, identifying any strategic changes of direction such as policies which intensify or de-intensify exploitation of deep seabed minerals in a particular region of ABNJ and maintaining continuous engagement with relevant stakeholders over the medium to longer term to ensure transparent governance.

The Chair's streamlined non-paper ${ }^{47}$ on 'Elements of a draft text of an international legally-binding instrument under the United Nations Convention on the Law of the Sea on the conservation and sustainable use of marine biological diversity of areas beyond national jurisdiction, ${ }^{38}$ issued for the fourth

\footnotetext{
44 Ibid $48-49$.

$45 \quad$ Ibid $53-54$.

$46 \quad$ Ibid $55^{-5}$.

47 In diplomatic parlance, a 'non-paper' is a document typically put forward without explicit attribution in international negotiations.

48 undoalos, Preparatory Committee, 'Chair's streamlined non-paper on elements of a draft text of an international legally-binding instrument under the United Nations Convention on the Law of the Sea on the conservation and sustainable use of marine biological diversity of areas beyond national jurisdiction', http://www.un.org/Depts/los/ biodiversity/prepcom_files/Chairs_streamlined_non-paper_to_delegations.pdf.
} 
Preparatory Committee meeting reflects the lack of consensus among participant States on whether to include provisions on SEA in a future ILBI. It contains two options with the first excluding provisions on SEAs. The second option provides for the conduct of SEAs under the following conditions:

- Clear, transparent and effective requirements and procedures for SEAs would be established.

- The parameters for EIAs in the instrument would equally apply to SEAs.

- Cooperation between States at the regional level would be facilitated, either ad hoc or in the context of existing regional or global institutions, for conducting SEAs in areas beyond national jurisdiction.

- SEAs would be developed at the regional level, prior to commencing activities requiring EIAs.

- Regional and global organizations would be encouraged to prepare SEAs where they have mandates.

- Mechanisms would be established in the instrument to engage global sectoral organizations, such as IMO and ISA, as well as regional conventions in regional SEA processes.

- SEAs would be collectively funded. ${ }^{49}$

The non-paper also envisages the establishment of an SEA/EIA administrative oversight body which could 'ensure that the EIA and SEA processes would be properly conducted by the appropriate entities and provide advice to a global body on EIAS and SEAs'. ${ }^{50}$

In discussions on a revised Chair's text containing draft recommendations to the UN General Assembly, focusing on the ILBI draft elements at the fourth Preparatory Committee meeting, opinions of delegates on including provisions on SEAs were quite divergent with diametrically opposed views emerging on whether the new instrument should address SEAs in ABNJ. While the Caribbean Community (CARICOM) called for stronger language on SEA $\mathrm{s}$ in the Chair's draft text on the elements of the ILBI, the US, supported by China, but opposed by the Pacific Small Island Developing States and Senegal, proposed deleting the section due to lack of consensus and insufficient information on how SEA s can be part of an international process. ${ }^{51}$ Midway through the second week of the fourth Preparatory Committee meeting, the European Union, with CARICOM, Argentina, New Zealand and Iran, opposed the US and China's proposal to delete the section, with Australia, supported by Norway, suggesting a footnote, clarifying that the issue of sEAs could be considered in a different

\footnotetext{
49 Ibid Part III, Section E.7.

$50 \quad$ Ibid Part III, Section E.4.

51 IIsD Summary, above (n 9).
} 
section of the ILBI, for example under area based management tools. ${ }^{52}$ The final outcome document of the fourth Preparatory Committee included nonexclusive elements of a draft ILBI text that generated convergence among most delegations, a list of main issues on which there is divergence of views, with the indication that neither of these sections reflect consensus among participants; and a recommendation to the UN General Assembly to take a decision, as soon as possible, on the convening of an Intergovernmental Conference (IGC). ${ }^{53}$ SEA s were included in the list of main issues on which there is a divergence of views. ${ }^{54}$ There could be a number of reasons for this, including a lack of understanding or vision of how SEAS could work in ABNJ and the substantial costs of undertaking and implementing SEAs which would fall on States Parties in the case of SEAs rather than on private sector proponents of activities as is the case with EIAs. There could also be differences of perspective on the scope and components of SEA among States participating in the ILBI negotiations, for instance, over stakeholder engagement or whether an SEA should consider cumulative impacts. ${ }^{55}$

The state of flux on the potential elements of an ILBI in the Preparatory Committee work has settled to some extent during the first three meetings of the IGC. However, this does not extend to the issue of what SEA elements might be included in the ILBI. The latest draft text accompanying the President's Note, still frames the commitment to SEAs as subject to discussion. ${ }^{56}$ Reports of the negotiations show that different views remain on the extent to which the ILBI should detail the obligation to conduct environmental assessments in general. ${ }^{57}$ Views diverge on the extent to which the process should be internationalized, for example, through a scientific and technical body, and whether minimum or common standards should be adopted. Whilst there appears to be growing support for the inclusion of a specific provision on SEAs, questions remain about how such assessments would be implemented in practice. ${ }^{58}$

\footnotetext{
52 Ibid.

53 Ibid.

54 Ibid.

55 See above (n 33). These issues have certainly been obstacles to realizing SEA in the Antarctic context.

56 UNGA, Draft text of an agreement under the United Nations Convention on the Law of the Sea on the conservation and sustainable use of marine biological diversity of areas beyond national jurisdiction, UN Doc A/CONF.232/2019/6 (17 May 2019).

57 UNGA, Statement by the President of the conference at the closing of the third session, UN Doc A/CONF.232/2019/10 (13 September 2019) 13-55.

$5^{8}$ Ibid 15 .
} 


\section{$9 \quad$ Conclusion}

The implementation of the environmental assessment provisions of the ILBI is likely to require a high degree of collaboration between individual States Parties and global and regional organizations with ABNJ responsibilities. This may not necessarily involve displacing existing environmental assessment regimes and practice but rather adding $\mathrm{ABNJ}$ considerations to current environmental assessment processes where they exist and providing best practice guidelines for processes such as EIA and SEA. ${ }^{59}$ The challenges involved in implementing SEA for policies, plans and programmes in ABNJ are significant due to multiple factors such as the vast geographic areas involved, the significant knowledge gaps on deep sea biodiversity, the sparse and fragmentary governance framework currently in place, the lack of resources and technical capacities to implement strategic options and the nascent stage of many activities in ABNJ. For these reasons, SEA for particular sectors and regions of ABNJ may only evolve over the longer term as knowledge of deep sea biodiversity increases and the necessary resources and governance structures are in place.

59 R Rayfuse and R Warner, 'Securing a Sustainable Future for the Oceans beyond National Jurisdiction: The Legal Basis for an Integrated Cross-Sectoral Regime for High Sea Governance for the Twenty First Century' (2008) 23(3) International Journal of Marine and Coastal Law 420-421; KN Scott, 'International Environmental Governance: Managing Fragmentation Through Institutional Connection' (2011) 12(1) Melbourne Journal of International Law $5^{-6 .}$ 